\title{
ANÁLISE ESPAÇO-TEMPORAL DA ÁREA COLHIDA E PRODUÇÃO DE FEIJÃO CAUPI (Vigna unguiculata (L.) Walp.) DA MICRORREGIÃO DO GUAMÁ NO PERÍODO DE 2003-2015
}

\section{SPACE-TEMPORAL ANALYSIS OF THE COLLECTED AREA AND CAUPI BEAN PRODUCTION (Vigna unguiculata (L.) Walp.) FROM THE MICROREGION OF GUAMÁ IN THE PERIOD 2003-2015}

\author{
Gutierre Pereira Maciel ${ }^{1}$; Francisco Adriano Cavalcante da Silva ${ }^{2}$; Antônio Jean Mota de \\ Lima $^{3}$; Maria do Socorro Pires Souza ${ }^{4}$; Wanderson Cunha Pereira ${ }^{5}$
}

DOI: $\underline{\text { https://doi.org/10.31692/978-65-991061-7-0.232-240 }}$

\section{RESUMO}

As leguminosas são de grande importância social e econômica para o país, isso se deve ao fato de estar presente na dieta alimentar humana e serem ricas em proteínas, ferro e outros minerais. O feijão caupi é cultivado principalmente nas regiões Norte e Nordeste, as quais são as maiores produtoras do Brasil. Este trabalho tem como principal objetivo analisar espacial e temporalmente a dinâmica da área colhida e produção de feijão caupi na Microrregião do Guamá, Nordeste Paraense, no período de 2003-2015. Os dados foram obtidos do Instituto Brasileiro de Geografia e Estatística (IBGE), foram tabulados em planilha eletrônica a fim de gerar as análises prévias dos dados e posteriormente processados utilizando-se o sistema de informação geográfica QGIS (Quantum GIS, versão 2.18.12) a fim de gerar os mapas espaciais dos mesmos. Após as análises, verificou-se que a atividade agrícola de produção de feijão caupi sofreu acentuada queda de 2003 a 2009, tanto em relação à produção quanto para área colhida. Observou-se, ainda, que a produção de feijão caupi acompanhou a redução da área cultivada e colhida. Essa queda de produção da região é alarmante para o Estado do Pará, tendo em vista a importância da cultura na segurança alimentar frente ao crescimento populacional ascendente, o qual demandará por mais alimento. É fundamental que estes resultados sensibilizem autoridades governamentais competentes, e percebam a emergência do setor. O uso de geotecnologias é importante para o setor de produção de grãos de feijão caupi pois torna a informação mais clara e didática, o que contribui para direcionar e fundamentar a gestão da cadeia produtiva do setor, quer seja por parte dos agricultores, quer seja pelo Estado.

Palavras-Chave: Leguminosas, Geografia, Geoprocessamento.

\section{ABSTRACT}

The legumes are of great social and economic importance for the country, this is due to the fact that it is present in the human diet and rich in proteins, iron and other minerals. The Cowpea bean is grown mainly in the North and Northeast, which are the largest producers in Brazil. This paper has as main objective to analyze spatially and temporally the dynamics of the harvested area and cowpea production in the Guamá Microregion, Northeast of Paraense, in the period of 2003-2015. The data were taken from the Brazilian Institute of Geography and Statistics (IBGE), tabulated in a spreadsheet to generate the previous data analysis and later processed using the QGIS (Quantum GIS, version 2.18.12) in order to generate spatial

\footnotetext{
${ }^{1}$ Agronomia, Universidade Federal Rural da Amazônia (UFRA), gutierre_maciel@ hotmail.com

${ }^{2}$ Sistema de Informação, Universidade Federal Rural da Amazônia (UFRA), adrianocavalcantes@ hotmail.com

${ }^{3}$ Agronomia, Universidade Federal Rural da Amazônia (UFRA), jeantonheiro@ hotmail.com

${ }^{4}$ Agronomia, Universidade Federal Rural da Amazônia (UFRA), piressoc@yahoo.com.br

${ }^{5}$ Mestre, Universidade Federal Rural da Amazônia (UFRA), wanderson.pereira@ufra.edu.br
} 
maps of them. After the analyzes, it was verified that the agricultural activity of cowpea production suffered a sharp drop from 2003 to 2009, both in relation to production and area harvested. It was also observed that the production of cowpea beans accompanied the reduction of cultivated and harvested area. This fall in production in the region is alarming for the State of Pará, given the importance of culture in food security in the face of increasing population growth, which will demand more food. It is essential that these results sensitize competent government authorities, and realize the emergency of the sector. The use of geotechnologies is important for the sector of cowpea bean production, since it makes the information clearer and didactic, which contributes to directing and informing the management of the productive chain of the sector, whether by the farmers or by the state.

Keywords: Legumes, Geography, Geoprocessing.

\section{INTRODUÇÃO}

As leguminosas apresentam grande importância social e econômica para o país, pois enriquecem a dieta alimentar humana por serem ricas em proteínas, ferro, entre outros minerais, e sua cadeia produtiva gera emprego e renda, o que contribui para o desenvolvimento regional (SILVA \& OLIVEIRA, 1993; PHILLIPS et al., 2003; FREIRE FILHO et al., 2009).

O feijão caupi é uma cultura rústica nativa da África, bastante cultivado nos continentes africano, americano e asiático, reflexo das necessidades nutricionais de seus povos (FREIRE FILHO et al., 2005; SILVA et al., 2008). É usado, ainda, como feno, silagem e adubação verde (ANDRADE JÚNIOR, 2000).

De acordo com Rosa (2011), a geotecnologia refere-se ao conjunto de tecnologias para coleta, processamento, análise e disponibilização de informações geográficas. Além disso, possui custo de implantação relativamente baixo e agilidade na produção de resultados (CASTANHO; TEODORO, 2010).

Essa ferramenta, através da elaboração de mapas, contribui para o planejamento rural e para compreender o dinamismo da produção agrícola, pois oferece uma visão mais ampla da situação e alterações que ocorrem no setor durante um determinado período de tempo.

As mudanças que ocorrem no uso e ocupação do solo interferem direta e indiretamente as atividades econômicas da região, e devem der investigadas a fim de conhecer suas causas e consequências.

O estudo objetivou analisar espacial e temporalmente a dinâmica da área colhida e produção de feijão caupi na Microrregião do Guamá, Nordeste Paraense, no período de 2003 2015 . 


\section{FUNDAMENTAÇÃO TEÓRICA}

O feijão caupi também conhecido como feijão-macassar ou feijão-de-corda é um alimento fundamental na dieta alimentar da população de baixa renda, em especial da zona rural das regiões Norte e Nordeste do Brasil, as quais são as principais regiões produtoras (FREIRE FILHO et al., 2011). Além disso, é uma leguminosa presente em mais de 100 países, sendo boa fonte de proteínas, carboidratos, rico em fibras, vitaminas e minerais (COHEN et al., 1991; EMBRAPA MEIO NORTE, 2003; SINGH, 2007; FROTA et al., 2008).

O Brasil é um produtor de destaque no cenário mundial, contudo, os 5 países maiores produtores de feijão caupi são a Nigéria, Niger, Burkina Faso, Tanzânia e Mianmar (FAO, 2015). De acordo com a CONAB (2017), o Estado do Pará, no agrícola de 2016, com 25 mil hectares produziu 18,7 mil toneladas de feijão caupi, o que representa 57,34\% da produção da Região Norte e apenas $2 \%$ da produção nacional. O rendimento médio foi de $746 \mathrm{Kg} / \mathrm{ha}$, o qual está acima da média nacional $(291 \mathrm{Kg} / \mathrm{ha})$, porém, abaixo das regiões Norte $(801 \mathrm{Kg} / \mathrm{ha})$ e Sudeste $(900 \mathrm{Kg} / \mathrm{ha})$.

É fundamental inserir a tecnologia no processo produtivo para aumentar o rendimento da atividade (MATOS FILHO, 2009). Em geral, nas áreas produtoras de feijão caupi na Microrregião do Guamá, Nordeste Paraense, os solos são ácidos, pobres em nutrientes e com presença de alumínio tóxico. O emprego da calagem corrige a fertilidade do solo e ajuda na obtenção de safras fartas. É importante, ainda, o uso de sementes certificadas, inoculante, máquinas agrícolas e espaçamento adequado (SILVA et al., 2006; ZILLI et al., 2009; BEZERRA et al., 2009).

O setor agrícola do Estado do Pará busca atender a ascendente demanda por alimentos e reduzir o êxodo rural, para tanto, torna-se imprescindível analisar a dinâmica do setor (FILGUEIRAS et al. 2003), com o intuito de detectar os problemas e tomar as medidas cabíveis.

\section{METODOLOGIA}

A Microrregião do Guamá, localizada no Nordeste Paraense ( $01^{\circ} 44^{\prime} 04$ 'S, 4703'28" O e altitude $96 \mathrm{~m}$ ), foi a área de estudo deste trabalho. Os dados temporais dessa região referentes a área colhida, em hectare (ha), e a produção, em tonelada (t), de feijão caupi, entre os anos de 2003 e 2015, foram obtidas no site Pará Sustentável e plotados em planilha eletrônica (PARÁ SUSTENTÁVEL, 2018). Para o processamento e análise desses dados foi utilizado o sistema de informação geográfica QGIS (Quantum GIS, versão 2.18.12). Além 
disso, a base cartográfica municipal da Microrregião do Guamá foi obtida no site do IBGE (IBGE, 2018). A figura apresenta 01 apresenta a Microrregião do Guamá e sua divisão municipal.

Figura 01. Divisão da Microrregião do Guamá, Nordeste Paraense. Fonte Própria.

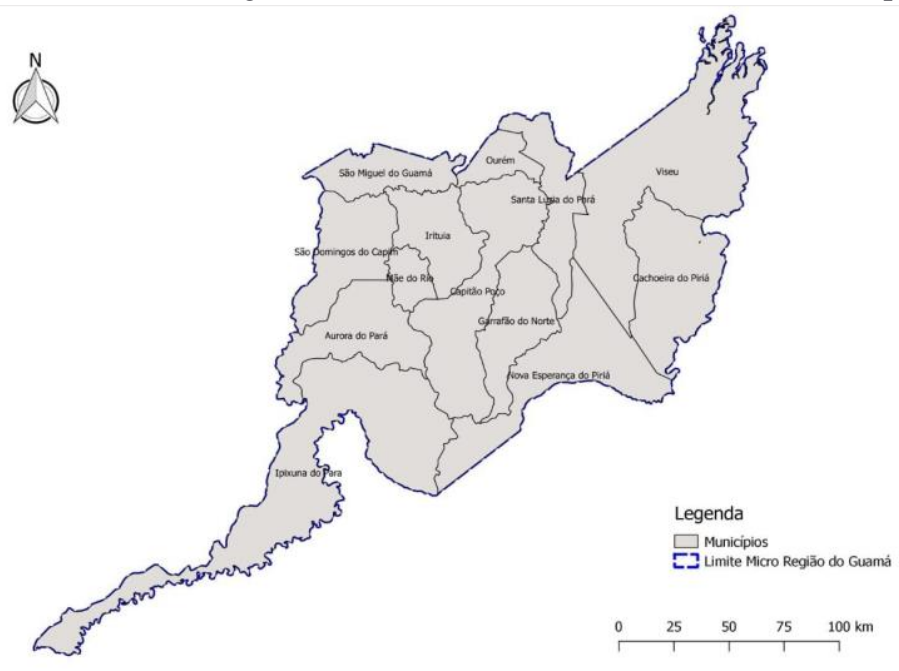

Os dados obtidos não sofreram nenhuma conversão ou mudança de unidade. Todos os municípios que compõem a área de estudo apresentaram valores de área colhida e produção, os quais não foram constatados em alguns anos do período avaliado. Para estes casos, adotouse o valor zero.

Após a padronização dos dados, estes foram associados a carta cartográfica municipal da Microrregião do Guamá e alocados para o software QGIS. Por conseguinte, foram gerados os mapas para os anos de 2003, 2009 e 2015, os quais foram escolhidos por representarem melhor dinâmica da produção de feijão caupi no período estudado, fundamental para detecção de contrastes.

Os municípios foram alocados em classes para formulação de cada tipo de gráfico, área colhida $(0-250 ; 250-500 ; 500-1.250 ; 1.250-2.500 ; 2.500-4000)$, em hectare, e produção (0-250; 250-500; 500-1.000; 1.000-2.000; 2.000-6.000), em toneladas.

A metodologia deste estudo baseou-se no trabalho de Souza et al. (2009), que objetivaram avaliar e detectar padrões espaciais de área plantada e produção cafeeira no estado de Minas Gerais, entre os anos de 1990 e 2009.

\section{RESULTADOS E DISCUSSÕES}

Observa-se que a atividade agrícola de produção de feijão caupi sofreu acentuada queda de 2003 a 2009 (Gráfico 1), tanto em relação à produção quanto para área colhida. De 2009 a 2015 houve certa estabilidade no setor. Moreira et al. (2017), avaliando a evolução da 
produtividade de feijão caupi na região do Nordeste Paraense no período de 2000 a 2014, observaram redução na produção e área plantada, resultado também constado por Rebello et al. (2011).

Gráfico 1. Variação da produção e área colhida de feijão caupi na Microrregião do Guamá de 2003-2015.

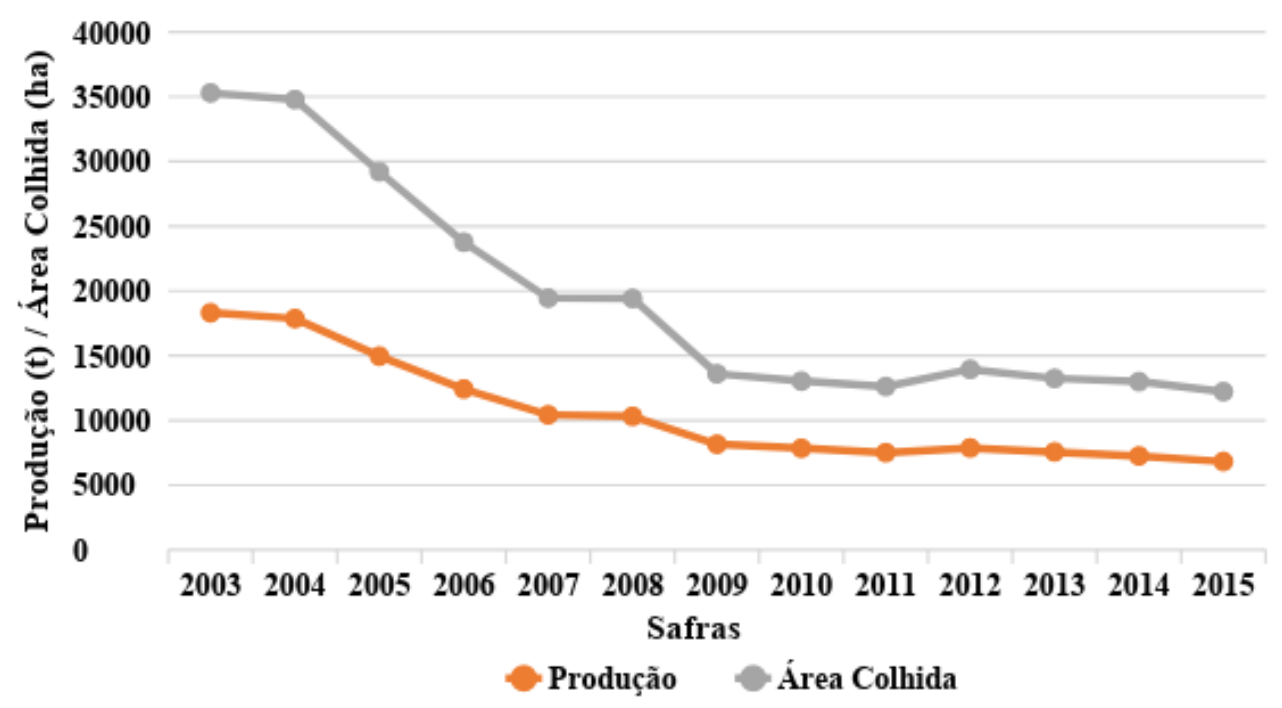

Na Microrregião do Guamá, a redução da área plantada e, por conseguinte, área colhida (Figuras 2, 3 e 4), pode estar associada especialmente com a tomada de decisão dos agricultores, os quais optam por cultivar culturas com preço mais atrativo ou que apresentem potencial econômico e estejam em plena ascensão no mercado, a exemplo de espécies anuais, como a mandioca (Manihot esculenta), e espécies perenes, como o açaizeiro (Euterpe oleracea Mart.), pimenteira-do-reino (Piper nigrum), dendezeiro (Elaeis guineensis Jacq.), e espécies cítricas (Citrus Spp.).

De acordo com Silva e Navegantes-Alves (2017), no Nordeste Paraense, a expansão da dendeicultura empresarial interfere na autonomia dos agricultores, os quais deixam de produzir seu próprio alimento e passam a compra-los com a renda obtida na nova atividade. Uma alternativa para diversificação alimentar seria o consórcio com feijão caupi, porém, essa ideia não é aceita pelas empresas que usam a monocultura como modelo de produção agrícola. 
Figura 2. Área Colhida - 2003

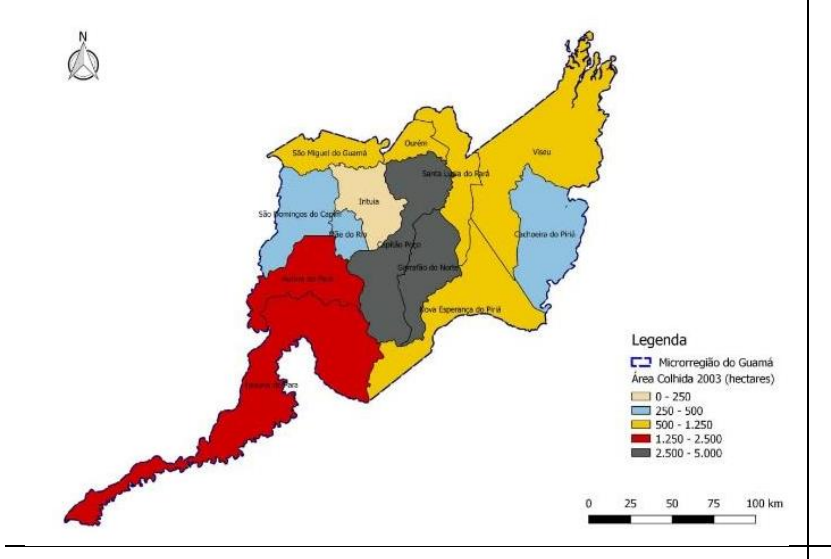

Figura 4. Área Colhida - 2015

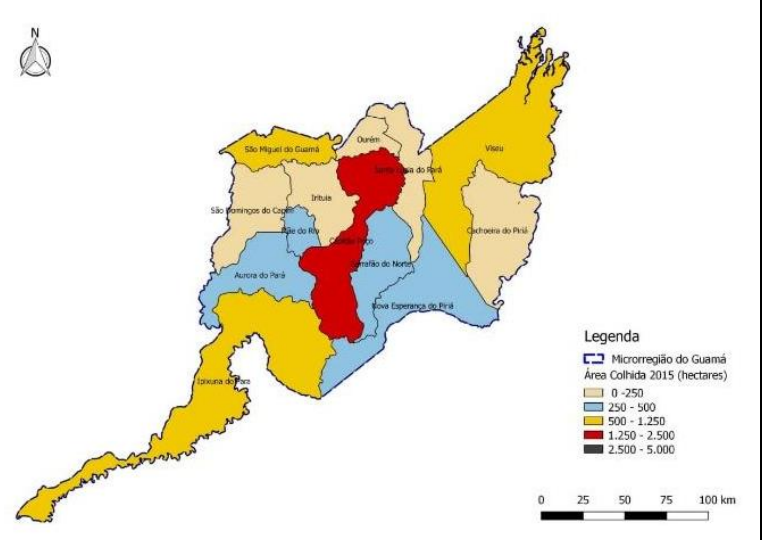

Figura 3. Área Colhida - 2009

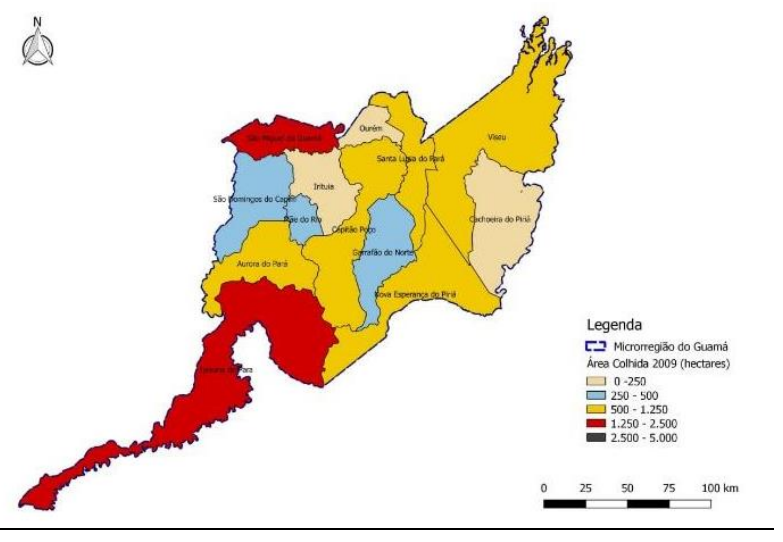

Gráfico 3. Distribuição da Área Colhida 2003-2015

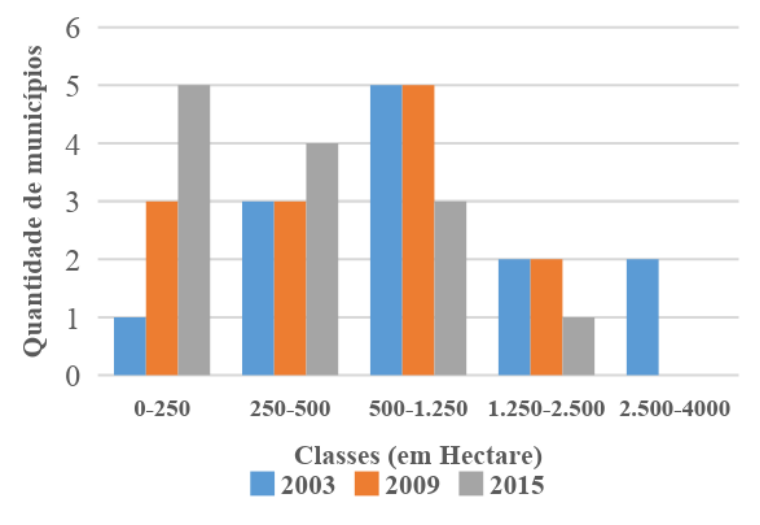

Observa-se, ainda, que a produção de feijão caupi acompanhou a redução da área cultivada e colhida (Figuras 5, 6 e 7). Essa queda de produção da região é alarmante para o Estado do Pará, tendo em vista a importância da cultura na segurança alimentar frente ao crescimento populacional paraense ascendente, o qual demandará por mais alimento, mas talvez haverá escassez do produto em futuro próximo.

É essencial que estes resultados sensibilizem autoridades governamentais competentes, e percebam a emergência do setor. Uma saída seria o investimento em um material genético mais produtivo, ou seja, pode-se produzir mais com menos área (FREIRE FILHO et al., 2007). Outra medida para alavancar a produção na região refere-se à adoção de políticas públicas que favoreçam o acesso ao crédito, máquinas agrícolas e sementes certificadas, ou seja, são atitudes governamentais que visam o aumento da produção e produtividade. 


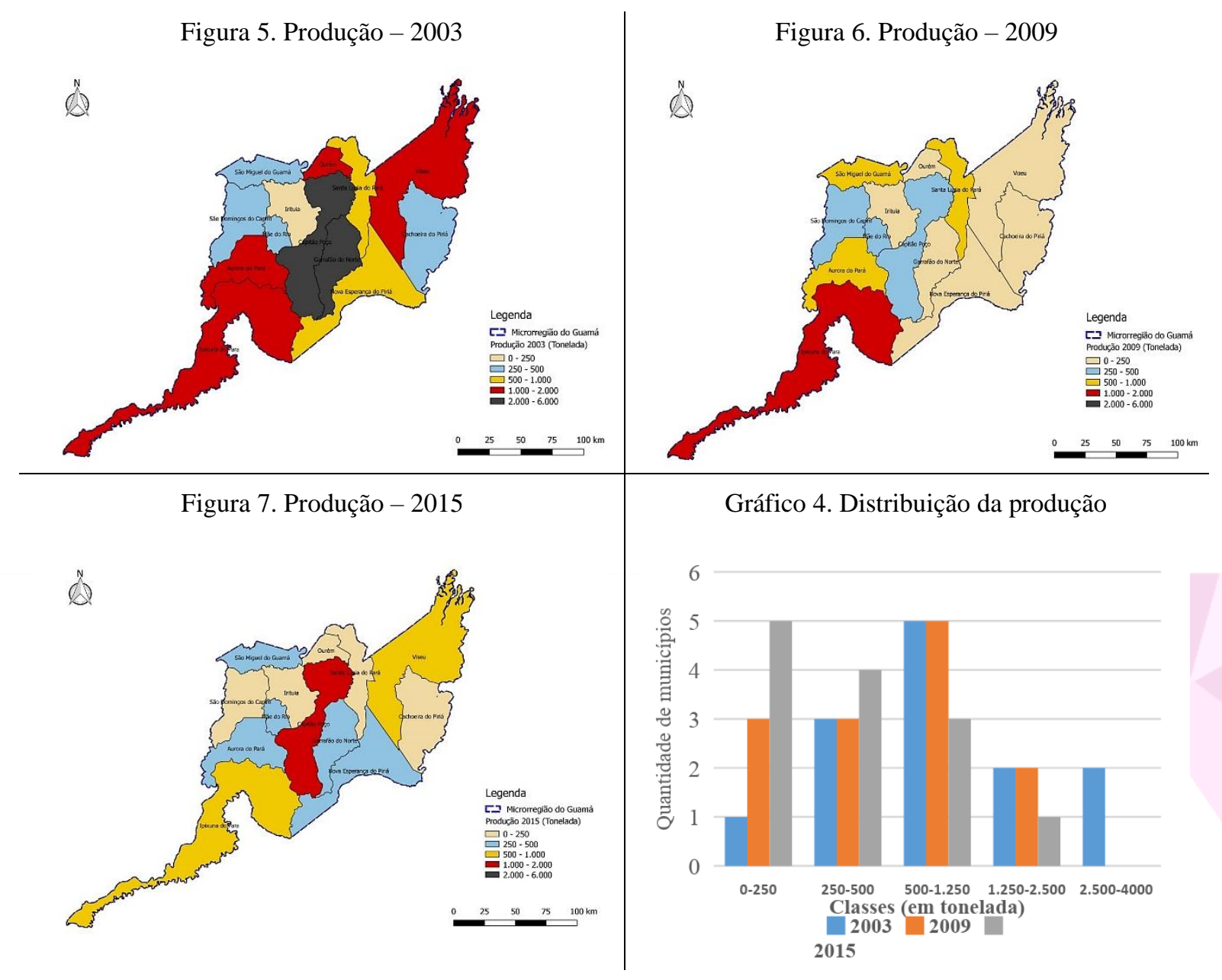

Embora o nível de tecnologia aplicado no processo produtivo seja baixo, esse não é o único fator que explica a redução da produção de feijão caupi na Microrregião do Guamá. A pesquisa elaborada por órgãos de pesquisa, seja pública ou privada, não chega ao produtor, que fica a margem de uma agricultura de alta produtividade.

Além disso, a assistência técnica não vem realizando seu papel como deveria, porque falta estrutura adequada e o serviço conta com baixo contingente de técnicos, insuficiente para atender a demanda da região. Muitos produtores não possuem conhecimento mínimo acerca inoculante e seu reconhecido benefício no aumento da produção de feijão caupi (SILVA et al., 2006; ZILLI et al., 2009).

Outro fator que corrobora para a queda do setor é a ausência de organizações cooperadas (MOREIRA et al., 2017), ideal para a prosperidade da agricultura familiar, principal responsável pela produção da leguminosa na região.

\section{CONCLUSÕES}

A análise espacial dos dados é uma ferramenta que auxilia e melhora a compreensão da dinâmica da produção de feijão caupi, pois permite uma visão integrada das informações. 
O uso de geotecnologias é importante para o setor de produção de grãos de feijão caupi pois torna a informação mais clara e didática, o que contribui para direcionar e fundamentar a gestão da cadeia produtiva do setor, quer seja por parte dos agricultores, quer seja pelo Estado.

\section{REFERÊNCIAS}

BEZERRA, A. A. C; TÁVORA, F. J. F; FREIRE FILHO, F. RODRIGUES; RIBEIRO, V. Q. Características de dossel e de rendimento em feijão-caupi ereto em diferentes densidades populacionais. Disponível em: <http://www.scielo.br/pdf/pab/v44n10/v44n10a05.pdf>. Acesso em 22/09/2018.

CASTANHO, R. B. TEODORO, M. A. O uso de geotecnologias no estudo da produção agropecuária. Brazilian Geographical Journal: Geosciences and Humanities Research Médium, v. 1, p. 136-153, 2010.

COHEN, J. I.; WILLIAMS, J. T.; PLUCKNETT, D. L.; SHANDS, H. Ex situ conservation of plant genetic resources: global development and environmental concerns. Science, Washington, v. 253, n. 5022, p. 866-872, Aug. 1991. Disponível em: http://www.joelcohen.org/pdf/ExSituConservation.pdf. Acesso em: 10 ago. 2010.

CONAB. Observatório agrícola: acompanhamento da safra brasileira de grãos. V. 4 - SAFRA 2016/17- N. 8 - Oitavo levantamento, Brasília, p. 1-144, maio, 2017.

EMBRAPA MEIO-NORTE. Cultivo de feijão caupi. Jul/2003. Disponível em: <http://www.cpamn.embrapa.br/pesquisa/graos/ FeijaoCaupi/referencias.htm>. Acesso em: 10 set. 2018.

FAO (2015). FAOSTAT. Crops. Cow peas, dry. Disponível em: http://faostat3.fao.org/browse/Q/QC/E. Acesso em 22 de setembro de 2018.

FREIRE FILHO, F. R. et al. Feijão-caupi no Brasil: produção, melhoramento genético, avanços e desafios. Embrapa Meio-Norte, Teresina, 84 p, 2011.

FREIRE FILHO, F. R.; CRAVO, M. S.; RIBEIRO, V. Q.; ROCHA, M. M.; CASTELO, E. O.; BRANDÃO, E. S.; BELMINO, C. S.; M. Í. S. MELO. BRS Milênio e BRS Urubuquara: cultivares de feijão-caupi para a região Bragantina do Pará. Rev. Ceres, Viçosa, v. 56, n.6, p. 749-752, nov/dez, 2009.

FREIRE FILHO, F. R.; LIMA, J. A. A.; RIBEIRO, V. Q. Feijão-caupi: avanços Tecnológicos. Brasília: Embrapa Informação Tecnológica, 2005. 519 p.

FROTA, K. M. G.; MENDONÇA, S.; SALDIVA, P. H. N.; CRUZ, R. J.; ARÊAS, J. A. G. Cholesterol-lowering properties of whole cowpea seed and its protein isolate in hamsters. Journal of Food Science, Chicago, v. 73, n. 9, p. H235-H240, Nov./Dec. 2008. 
IBGE, Instituto Brasileiro de Geografia e Estatística. Banco de Dados Agregados - Sistema de Recuperação Automática - SIDRA. Brasília, 2018. Disponível em: < http://www.sidra.ibge.gov.br/ >. Acesso em: 24, set. 2018.

MATOS FILHO, C. H. A.; GOMES, R. L. F.; ROCHA, M. M.; FREIRE FILHO, F. R.; LOPES, Â. C. A. Potencial produtivo de progênies de feijão-caupi com arquitetura ereta de planta. Ciência Rural, Santa Maria, v.39, n.2, p.348-354, mar-abr, 2009.

MOREIRA, W. K. O.; OLIVEIRA, S. S.; ALVES, J. D. N.; RIBEIRO, R. A. R; OLIVEIRA, I. A.; SOUSA, L. A. S. Evolução da produtividade do feijão-caupi para os principais produtores do nordeste paraense no período de 2000 a 2014. Nucleus, v. 14, n.1, abr.2017.

PHILLIPS, R. D. et al. Utilization of cowpeas for human food. Field Crops Research, v. 82, n. 2, p. 193-213, 2003.

REBELLO, F. K.; DOS SANTOS, M. A. S.; HOMMA, A. K. O. Modernização da agricultura nos municípios do nordeste paraense: determinantes e hierarquização no ano de 2006. Revista de Economia e Agronegócio-REA, v. 9, n. 2, 2011.

ROSA, R. Análise espacial em geografia. Revista da ANPEGE, v. 7, n. 1, p. $275-289$, 2011.

SILVA, E. M.; NAVEGANTES-ALVES, L. F. Organização e diversidade dos sistemas de produção de agricultores familiares integrados à agroindústria de dendê no nordeste paraense. Revista Brasileira de Gestão e Desenvolvimento Regional. G\&DR • Taubaté, SP, Brasil. v. 14, n. 1, p. 166-192, jan-abr/2018.

SILVA, P. S. L.; OLIVEIRA, C. N. Rendimentos de feijão verde e maduro de cultivares de caupi. Horticultura Brasileira, Brasília, v. 11, n. 2, p 133-135, 1993.

SILVA, R. P. et al. Efetividade de estirpes selecionadas para feijão caupi em solo da região semi-árida do sertão da Paraíba. Revista Brasileira de Ciências Agrárias, Recife, v. 3, n. 2, p. 105-110, 2008.

SILVA, V. N.; SILVA, L. E. S. F.; FIGUEIREDO, V. B. Atuação de rizóbio com rizobactéria promotora de crescimento em plantas na cultura do caupi (Vigna unguiculata [L.] Walp.). Acta Scientiarum Agronomy, v. 28, n. 03, p. 407-412, 2006.

SINGH, B. B. Recent progress in cowpea genetics and breeding. Acta Horticulturae, The Hague, n. 752, p. 69-76, 2007. Edition of the Proceedings of the International Conference on Indigenous Vegetables and Legumes, Hyderabad, India, Sep. 2007. Disponível em: http://www.actahort.org/books/752/752_7.htm

SOUZA, Va. C. O.; VIEIRA, T. G. C.; ALVES, H. M. R.; VOLPATO, M. M. L. Análise espaço-temporal da cafeicultura mineira: 1990-2009. VI Simpósio de Pesquisa dos Cafés do Brasil, 2009.

ZILLI, J. E. et al. Contribuição de estirpes de rizóbio para o desenvolvimento e produtividade de grãos de feijão-caupi em Roraima. Acta Amazonica, v. 39, n. 04, p. 749-758, 2009. 